\title{
Fuentes para el estudio del quichua y su papel en la evangelización en el caso ecuatoriano. Una visión panorámica
}

\author{
Sources for the study of the Kichwa language and its \\ evangelizing role in Ecuador. An overview
}

Fontes para estudo do quíchua e o seu papel na evangelização no caso equatoriano. Uma visão panorâmica

\section{Luis Fernando Garcés Velásquez \\ Universidad Politécnica Salesiana lgarcesv@ups.edu.ec}

DOI: http: / / dx.doi.org/10.29078/rp.v0i48.701

Fecha de presentación: 26 de octubre de 2017

Fecha de aceptación: 29 de septiembre de 2018

Artículo de investigación 
RESUMEN

El artículo considera los testimonios dejados por los agentes eclesiales de la Colonia y el primer siglo republicano para el estudio del quichua ecuatoriano. Este corpus permite rastrear algunos aspectos de la historia de esta lengua, los cambios lingüísticos internos y la ideología lingüística que acompañaba su difusión. Para ello, se muestra la manera en que la política lingüística andina se vinculó al proyecto evangelizador de la primera época colonial. En función de este proyecto se escribieron no solo textos catequísticos, sino gramáticas y vocabularios en las principales lenguas de los Andes.

Palabras clave: historia latinoamericana, historia del quechua, período colonial, evangelización, política lingüística, Audiencia de Quito, Ecuador.

ABSTRACT

The article considers the testimonies left by ecclesiastical agents of the Colony and the first century of the Republic regarding the study of the Ecuadorian Kichwa language. This body of documents makes it possible to trace back certain aspects of this language's history, internal linguistic shifts, and the linguistic ideology behind its dissemination. To this end, the article shows how Andean linguistic policy was linked to the evangelical missionary project of the early colonial period. On the basis of this project, not only were catechisms written, but also grammar books and glossaries, in the principal languages of the Andes.

Keywords: Latin American history, history of the Kichwa language, colonial period, evangelization, linguistic policy, Audiencia de Quito, Ecuador

RESUMO

O artigo considera as testemunhas deixadas pelos agentes eclesiásticos da colônia e do primeiro século republicano para o estudo do quíchua equatoriano. Esse corpus documental permite acompanhar alguns aspectos da história dessa língua, as mudanças linguísticas internas, além da ideologia linguística que faz parte da sua difusão. Para isso, o texto expõe a maneira que a politica andina vinculou-se para o projeto evangelizador na primeira época colonial. Em atenção para esse projeto, foram escritos no só textos para catequese, senão também gramáticas e vocabulários nas primeiras línguas andinas.

Palavras chave: História da América Latina, historia do quíchua, Colônia, evangelização, política linguística, Audiência de Quito, Equador. 


\section{INTRODUCCIÓN}

La mayor parte de los estudios sobre el quechua se han realizado desde variantes relevantes en términos de comprensión histórica del proceso de expansión lingüística inicial (las de la costa y sierra central peruana) y desde la variante que cumplió un rol político importante en el primer momento colonial: la surperuana. Las variantes "periféricas" han recibido menos atención (el ingano, el quichua ecuatoriano, el quichua del noroeste argentino).

Las fuentes para el estudio de dichas variantes periféricas suelen ser menos conocidas por los estudiosos de la lengua, no obstante contar con un respetable número de textos gracias a los cuales se pueden estudiar aspectos capitales como la historia externa, los cambios lingüísticos internos y la ideología lingüística que acompañó su difusión. El presente artículo busca dar cuenta del corpus que posibilita el estudio histórico del quichua ecuatoriano a partir de sus fuentes más representativas.

En un primer apartado, se muestra la manera en que la política lingüística andina se vinculó al proyecto evangelizador de la primera época colonial y cómo, desde ahí, se produjo un importante material normativo (gramáticas y vocabularios) en las principales lenguas andinas. Estos textos fueron "reducidos", durante el siglo XVIII, a las características específicas de la variante de la "provincia de Quito". Ya en la República se retoma el carácter evangelizador del quichua pero acompañado ahora por un interesante debate sobre las bondades o limitaciones de la lengua.

\section{Política lingüística Y EVANGeliZACión}

El interés de los misioneros coloniales por las lenguas indígenas estuvo marcado por su carácter instrumental. A los heraldos de la evangelización les interesaba aprender, apropiarse de las lenguas indígenas para poder evangelizar a los indios, a quienes se les consideraba paganos.

En el ámbito religioso fue donde se trabajó con mayor profundidad, donde hubo una política colonial relativamente intransigente. ${ }^{1}$ La principal tarea colonial, entonces, fue subalternizar las expresiones religiosas de los indios, la cual estuvo atada al proyecto de "conquista espiritual", donde fuera po-

1. Martín Lienhard, La voz y su huella. Escritura y conflicto étnico-cultural en América Latina 1492-1988, 3. ${ }^{a}$ ed. (Lima: Horizonte, 1992), 105. 
sible, o a la extirpación de idolatrías donde, según el criterio eclesiástico, no lo fuera. ${ }^{2}$

Así, el interés por las lenguas se concretó en una producción endógena en dos sentidos: por un lado, de gramáticas y vocabularios que permitían aprender las lenguas para reproducir las prácticas evangelizadoras de la Iglesia ${ }^{3}$ y, por otro lado, textos catequéticos y litúrgicos: doctrinas, confesionarios, catecismos, rituales, breviarios, etc., con los elementos fundamentales de la Iglesia que, bajo "correcta" traducción, eran herramientas de transmisión doctrinal. ${ }^{4} Y$ es que, como se sabe, son pocos los casos de una escritura quechua realizada por quechuas. ${ }^{5}$ Aparte de los textos que se pueden encontrar en las conocidas obras de Guamán Poma, ${ }^{6}$ Pachacuti $^{7}$ y los Ritos y tradiciones de Huarochiri, ${ }^{8}$ se cuenta con un corpus reducido de producción indígena en comparación con, por ejemplo, Mesoamérica. ${ }^{9}$

2. Véase Fernando Garcés, ¿Colonialidad o interculturalidad? Representaciones de la lengua y el conocimiento quechuas (La Paz: PIEB / Universidad Andina Simón Bolívar, 2009).

3. Véase Fernando Garcés, "Las letras, las palabras y el orden: acerca de ortografías, gramáticas y vocabularios quechuas", Página y signos 5, n. 7 (2011).

4. Véase Alan Durston, Pastoral Quechua. The History of Christian Translation in Colonial Peru, 1550-1650 (Notre Dame: University of Notre Dame Press, 2007).

5. Incluso estaba vinculada a aspectos religiosos. Véase Sabine Dedenbach-Salazar Sáenz, Entrelazando dos mundos. Experimentos y experiencias con el quechua de la cristianización en el Perú colonial (Quito: Abya-Yala, 2013). A lo largo del texto usaremos quechua para referirnos a la lengua como totalidad transdialectal, hablada actualmente en Colombia, Ecuador, Perú, Bolivia y Argentina, y quichua para referirnos a la variedad específica hablada en Ecuador.

6. Véase Felipe Guamán Poma de Ayala, "Nueva Coronica y Buen Gobierno, 1615", en The Guaman Poma Website, http://www.kb.dk/permalink/2006/poma/info/en/ frontpage.htm.

7. Véase Joan de Santa Cruz Pachacuti Yamqui Salcamaygua, Relacion de antiguedades deste reyno del Piru (Lima / Cusco: Instituto Francés de Estudios Andinos, IFEA / Centro de Estudios Regionales Andinos Bartolomé de Las Casas, CBC, 1993 [c. 1613]).

8. Véase Gerald Taylor, Ritos y tradiciones de Huarochirí del siglo XVII (Lima: Instituto de Estudios Peruanos, IEP, 1987).

9. Véase, sin embargo, Rodolfo Cerrón-Palomino, “Un texto desconocido del quechua costeño (s. XVI)", Revista Andina, n. 18 (1991): 393-413; Alan Durston, "La escritura del quechua por indígenas en el siglo XVII. Nuevas evidencias en el Archivo Arzobispal de Lima (estudio preliminar y edición de textos)", Revista Andina, n. 37 (2003); Alan Durston y George Urioste, "Las peticiones en quechua del curato de Chuschi (1678-1679)". En El quipu colonial. Estudios y materiales, ed. por Marco Curatola y José Carlos de la Puente (Lima: Pontificia Universidad Católica del Perú, PUCP, 2013); César Itier, "Lengua general y comunicación escrita: cinco cartas en quechua de Cotahuasi-1616", Revista Andina, n. ${ }^{\circ}$ 17 (1991): 65-107; Gerald Taylor, "Un documento quechua de Huarochirí-1607", Revista Andina, n. 5 (1985): 157-185. 
Para el caso del aimara, por ejemplo, Ludovico Bertonio publica su Vocabulario con el fin de contribuir a la gloria divina y de quitarles a los indios la ignorancia de su salvación y de los misterios de la Iglesia. En tal sentido, espera que su obra permita hablarles "congruentemente" a los indios, aunque no sea necesario saber todo de la lengua para enseñar la religión. ${ }^{10}$

Para el caso del quechua, el primer gramático de la lengua, Domingo de Santo Tomás, afirma que el objetivo de su obra es que los curas puedan difundir el Evangelio, aunque él no se sienta totalmente competente en la misma. Como veremos luego, hay un "indigenismo catequético" que obliga a instruir en quechua, lengua "sin la qual no se les puede predicar": "comencé a tractar de reduzir aquella lengua a arte para que no solamente yo pudiesse en ella aprovechar en aquella nueva iglesia, enseñando y predicando el Evangelio a los indios, pero otros muchos que, por la difficultad de aprenderla, no emprendían tan apostólica obra, viéndola ya en arte, y que fácilmente se podía saber, se animassen a ello, y con facilidad la aprendiessen, como se començó a hazer". ${ }^{11}$

quien supiere la grande y extrema necessidad que ay en aquellas provincias de la predicación del Evangelio, y quántos millares de ánimas se han ido y van al infierno por falta de conoscimiento dél y de las cosas de nuestra sancta fe cathólica por defecto de la lengua, sin la qual no se les puede predicar; y quántos buenos religiosos y siervos de Dios ay allá y acá, que se retraen desta sancta obra y temen poner el hombro a tan apostólica sementera como ésta, temiendo la difficultad de la lengua y creyendo no poder salir con ella: quien esto considerare atenta y christianamente y entendiere que esto que yo hago en querer redduzir esta lengua a arte y querer presentar ante vuestros ojos la fructa no enteramente madura y parir este concepto imperfecto que de la lengua tengo concebido antes de llegar a madurez y perfectión, es por la gran necessidad que ay della, y para dar alguna lumbre a los que ninguna tienen y mostrarles que no es difficultoso el aprenderla, y a animar a los que por falta / de la lengua están covardes en la predicación del Evangelio. ${ }^{12}$

El Anónimo de 1586 elabora un vocabulario por mandato del Concilio Limense de 1583. En él, lo interesante es que lo elabora no solo pensando en eclesiásticos sino también en seglares que tratan con los indios en los poblados.

Considerando [...] la necessidad que en estos reynos auia para la buena doctrina delos Naturales, y declaracion del Cathecismo Confessionario y Sermonario, que por decreto del Sancto Concilio Prouincial se hizo en esta Ciudad, he hecho este

10. Ludovico Bertonio, Vocabvlario de la lengva Aymara (Arequipa: El Lector, 2006 [1612]), 23-24.

11. Domingo de Santo Tomás, Grammatica o arte de la lengua general de los indios de los reynos del Peru (Lima: CBC, 1995 [1560]), 6.

12. Ibíd., 14-15. 
Vocabulario el mas copioso que ser pudo en la lengua Quichua y Española, con animo de hazer otro en la lengua Aymara que falta. El qual ser muy vtil para todo genero de gentes, assi Curas de yndios, como otras personas ecclesiasticas y seglares que vuieren de tratar con los yndios en poblado, y yendo de camino porque enel hallaran facilmente el vocablo que no entendieren, y tambien el de que tuuieren necessidad, para hablar. ${ }^{13}$

Finalmente, sobre este tema tenemos el testimonio de González Holguín. Como en los casos anteriores, el jesuita es movido por la necesidad de entregar herramientas para la evangelización: "La causa e intento Señor que me mouio a componer este vocabulario y arte [...] es ayudar a formar ministros del Euangelio para los indios, dandoles la copia y propiedad de la lengua que faltaua, con que no tengan ya alguna escusa para no predicar". ${ }^{14}$

Es claro que este autor no solo ha elaborado la Gramática para ejercer las funciones básicas de la comunicación o solo para entender el quechua. Su pretensión es que sus obras sirvan para lo fundamental: predicar.

Tanta baja y tan gran caida ha dado en la Iglesia del Peru el oficio apostolico de la predicacion con el daño de las almas que Dios solo conoce. Por lo cual, Señor, viendo yo y considerando este daño de las almas, y que era necesario que ayudasemos á su reparo todos, me he movido á componer esta arte enderezada no tanto á enseñar á los Curas para confesar, que para eso bastaba la que habia, sino para ayudar á lo que tanto deseo que reparemos que es la predicacion evangelica y apostolica, porqué con esta arte con sus adiciones de copia y elegancia con solo querer estudiar por si aunque sin maestro podrán los Curas saber para predicar y per-/ der el miedo que tienen los que no tienen copia ni saben la elegancia. ${ }^{15}$

En este contexto evangelizador, tanto la tradición oral quechua como la lengua misma fueron objeto "de una minuciosa e inteligente empresa de manipulación". ${ }^{16}$ A tal fin, los misioneros coloniales realizarán un intenso trabajo de adaptación léxica y de purificación semántica que les permita fijar el código de evangelización y dominio colonial. ${ }^{17}$ En este sentido, como dice Ta-

13. Arte, y vocabvlario en la lengva general del Perv llamada Quichua, y en la lengva Española (Lima: Antonio Ricardo, 1951 [1586]), 8.

14. Diego González Holguín, Vocabulario de la lengua general de todo el Peru llamada lengua qquichua o del inca, 3. a ed. (Lima: Universidad Mayor de San Marcos, 1989 [1608]), 5.

15. Diego González Holguín, Gramática y Arte Nueva de la Lengua General del todo el Peru llamada lengua Qquichua o Lengua del Inca, nueva edición revisada y corregida (Génova, 1842 [1607]), IX-X.

16. César Itier, "Estudio y comentario lingüístico". En Joan de Santa Cruz Pachacuti Yamqui Salcamaygua, Relación de antigüedades..., 172.

17. Véase Ruth Moya, "Estudio introductorio". En Alonso de Huerta, Arte breve de la lengua quechua, 2. ${ }^{a}$ ed. (Quito: Corporación Editora Nacional, CEN / Proyecto EBI, 1993 [1616]), XIII-XXXII; Taylor, Ritos y tradiciones de Huarochirí...; Gerald Taylor, Camac, ca- 
ylor, "es necesario tomar en consideración que los primeros evangelizadores no se preocupaban de la clarificación de los conceptos espirituales indígenas (que esperaban eradicar [sic]), sino de la imposición de conceptos cristianos, lo que explica la apropiación de un vocabulario religioso mal asimilado cuyos valores confusos se mantienen en el mundo híbrido del catolicismo andino hasta hoy". ${ }^{18}$

Veamos algunos ejemplos de lo dicho. ${ }^{19}$ La palabra shunku sunqu fue traducida como 'ánima' en la "Plática" que se ofrece al final de la Grammatica de Santo Tomás; sin embargo, posteriormente será usada para referirse a la "esencia" ${ }^{20}$ Lo propio ocurre con supay, que se generalizará con el significado de "diablo", cuando en la misma "Plática" de Santo Tomás aparece como un ser extranatural que puede ser bueno o malo. ${ }^{21}$ Sin embargo, el caso más representativo es aquel en que se busca expresar la idea de un Dios creador de la nada en la lengua andina. Según Itier, hay consenso entre varios estudiosos en que ningún término del quechua antiguo tuvo el valor de "crear" y menos de "crear de la nada". En tal sentido, "Los verbos utilizados por los misioneros para traducir este concepto son a menudo reinterpretaciones de un vocabulario religioso prehispánico que en su mayoría designaba la transmisión por las divinidades de una capacidad para cumplir ciertos fines" ${ }^{22}$ El concepto en cuestión se encuentra en la "Plática" de Santo Tomás, ${ }^{23}$ en las "Anotaciones" de la Doctrina Cristiana del Tercer Concilio Limense, ${ }^{24}$ en el Segundo Cántico del Símbolo Católico Indiano de Jerónimo de Oré ${ }^{25}$ y en la Relación de Antigüedades de Santa Cruz Pachacuti. ${ }^{26}$ En estos textos se pueden apreciar los distintos recursos lingüísticos de los que se sirvieron los evangelizadores para transmitir la idea de un Dios que crea ex nihilo.

Como se comprenderá, se trató de una ingente tarea de resementización que osciló entre cristianizar los términos andinos, traducir literalmente y pa-

may y camsca y otros ensayos sobre Huarochiri y Yauyos (Lima / Cusco: IFEA / CBC, 2000); Dedenbach-Salazar, Entrelazando dos mundos...

18. Taylor, Camac, camay y camsca..., 3.

19. Un desarrollo más detallado de los ejemplos que se muestran a continuación se puede encontrar en Garcés, ¿Colonialidad o interculturalidad?..., 15-21.

20. En el quichua actual shunku se traduce como "corazón". Para el diverso campo de significados y metáforas a partir de sunqu en el quechua boliviano, véase Fernando Garcés, De la voz al papel. La escritura quechua del Periódico CONOSUR Ñawpaqman (La Paz: CENDA / Plural, 2005).

21. Garcés, ¿Colonialidad o interculturalidad?..., 15.

22. Véase Itier, "Estudio y comentario lingüístico", 171.

23. Véase Santo Tomás, Grammatica o arte...

24. Véase Tercer Concilio Limense, Doctrina Christiana y Catecismo para la instrvccion de los Indios, y de las demas personas, que han de ser enseñadas en nuestra sancta Fé (Lima: Antonio Ricardo, Impressor, 1584).

25. Jerónimo de Oré, Symbolo Catholico Indiano (Lima: Antonio Ricardo, 1598).

26. Véase Pachacuti, Relacion de antigüedades... 
rafrasear términos cristianos. ${ }^{27}$ De tal forma que la traducción estuvo basada en una transferencia de sentido antes que en un sistema de palabra por palabra. ${ }^{28}$ En este contexto, la política lingüística colonial da lugar a una variante específica del quechua que Durston ha denominado "pastoral" y que se convierte en una lengua nueva y distintiva. ${ }^{29}$

En buena parte, la posición de la Iglesia y sus heraldos es similar a las narraciones anticonquista referidas por Pratt, ${ }^{30}$ en el sentido de que se trata de construcciones benévolas hacia los indios y sus lenguas.

Mi intento pues principal S. M. ofresceros este Artezillo ha sido, para que por el veays, muy clara y manifiestamente, quan falso es lo que muchos os han querido persuadir, ser los naturales de los reynos de Peru barbaros, \& indignos de ser tractados con la suauidad y libertad que los demas vassallos vuestros lo son. Lo cual claramente conoscera V. M. ser falso, si viere por este Arte, la gran policia que esta lengua tiene, La abundancia de vocablos, La conuenencia que tiene con las cosas que significan. Las maneras diuersas y curiosas de hablar. El suaue y buen sonido al oydo de la pronunciacion della, [...] Y si la lengua lo es, la gente que vsa della, no entre barbara, sino con mucha policia la podemos contar. ${ }^{31}$

La cita de Santo Tomás da cuenta de la relación entre lengua y hablantes; es decir, la concepción común de que determinada lengua lleva incorporada una serie de bondades que la hacen predilecta para determinadas tareas del intelecto o para la vivencia de determinadas virtudes morales. Es la idea que expresa el mestizo jesuita Blas Valera: "todos los indios que obedeciendo esta ley [de hablar el quechua] retienen hasta ahora la lengua del Cuzco son más urbanos y de ingenio más capaces, lo cual no tienen los demás". ${ }^{32} \mathrm{Su}$ afirmación, además, sería compartida por sacerdotes, jueces y corregidores del momento; ellos afirman

27. Véase Durston, Pastoral Quechua. The History...; Itier, "Estudio y comentario lingüístico".

28. Rodolfo Cerrón-Palomino, "Las primeras traducciones al quechua y al aimara". En Sobre las huellas de la voz. Sociolingüística de la oralidad y la escritura en su relación con la educación, comp. por Luis Enrique López e Ingrid Jung, 96-114 (Madrid / Cochabamba / Bonn: Morata / PROEIB Andes / DSE, 1998), 104-111.

29. Véase Durston, Pastoral Quechua. The History... También Dedenbach-Salazar, Entrelazando dos mundos...

30. Mary Louise Pratt, Ojos imperiales. Literaturas de viajes y transculturación (Ciudad de México: Fondo de Cultura Económica, 2010).

31. Santo Tomás, Grammatica o arte..., 8-9.

32. Blas Valera. En Inca Garcilaso de la Vega, Comentarios reales de los Incas, t. 3 (Lima: Mercurio, 1988 [1609]), 9. 
Que a los indios del Perú les es de tanto provecho [la lengua cortesana de los incas] como a nosotros la lengua latina, por que además del provecho que les causa en sus comercios, tratos y contratos, y en otros aprovechamientos temporales y bienes espirituales, les hace más agudos de entendimiento, y más dóciles, y más ingeniosos para lo que quisiesen aprender, y de bárbaros los truecan en hombres politicos y más urbanos. Y así los indios Puquinas, Collas, Urus, Yuncas y otras naciones, que son rudos y torpes, y por rudeza aun sus propias lenguas hablan mal, cuando alcanzan a saber la lengua del Cuzco, parece que echan de sí la rudeza y torpeza que tenían y que aspiran a cosas políticas y cortesanas, y sus ingenios pretenden subir a cosas más altas; finalmente se hacen más capaces y suficientes para recibir la doctrina de la fe católica, y cierto los predicadores que saben bien esta lengua cortesana, se huelgan de levantarse a tratar cosas altas y declararlas a sus oyentes sin temor alguno; porque así como los indios que hablan esta lengua tienen los ingenios más aptos y capaces, así aquel lenguaje tiene más campo y mucha variedad de flores y elegancias para hablar por ellas; y de esto nace que los Incas del Cuzco que la hablan más elegante y más cortesanamente reciben la doctrina evangélica en el entendimiento y en el corazón con más eficacia y más utilidad. ${ }^{33}$

Lo interesante es que las apreciaciones precedentes llevan ya marcada la distinción jerárquica entre distintos dialectos del quechua, tal como se aprecia en Alonso de Huerta: "Aunque la lengua Quichua, y General de el Inga, es vna, se ha de aduertir primero, que esta diuidida en dos modos de vsar en ella, que son, el vno muy pulido y congruo, y este llaman de el Inga, que es la lengua que se habla en el Cuzco, Charcas y demas partes dela Prouincia de arriua, que se dize Incasuyo. La otra lengua es corrupta, que la llaman Chinchaysuyo, que no se habla con la pulicia y congruidad que los Ingas la hablan". ${ }^{34}$

Sin embargo, no en todos los gramáticos de la época colonial se encuentran apreciaciones valorativas sobre las bondades del quechua. El jesuita González Holguín afirmaba: "Aduiertase que los indios no tenian vocablos de todo lo espiritual ni vicios, ni virtudes, ni de la otra vida y estados de ella". ${ }^{35}$ Y en 1579, fray Antonio de Zúñiga escribe una carta al rey Felipe II en la que se queja de que las lenguas nativas de los Andes ayudan a mantener las prácticas religiosas paganas; esto ocurre por el hecho de ser lenguas que expresan conceptos religiosos nativos y por no poseer el vocabulario apropiado para las ideas cristianas. Dice Zúñiga: "hay entre ellos lengua ninguna que sea bastante para declararles los misterios de nuestra Sancta Fe Católica,

33. Ibíd., 15. Énfasis añadido.

34. Alonso de Huerta, Arte breve de la lengua quechua, 2. ${ }^{a}$ ed. (Quito: CEN / Proyecto EBI, 1993 [1616]), 18.

35. González Holguín, Vocabulario de la lengua..., 10. 
por ser todas ellas muy faltas de vocablos". ${ }^{36}$ Para Zúñiga, el lenguaje de los indios ocupa el tercer lugar, luego de la coca y la brujería, en los impedimentos para la conversión religiosa. Las objeciones que presenta se refieren a que las lenguas nativas americanas son oscuras; no tienen términos para conceptos abstractos como tiempo, ser o virtud; no poseen términos para conceptos religiosos importantes como Dios, fe, ángel, virginidad o matrimonio; $\mathrm{y}$, no hay manera de expresar el concepto de Espíritu Santo. ${ }^{37}$

Como es de suponer, durante la Colonia fue la Iglesia la que tuvo prácticamente el monopolio productivo de las lenguas andinas en cuanto a publicaciones. Luego, con los procesos de independencia de las naciones andinas, hacia la segunda mitad del siglo XIX entran en escena agentes no eclesiásticos interesados en el quichua. A continuación presentamos un acercamiento a las fuentes con las que contamos para el estudio del quichua como lengua de evangelización.

\section{LOS PRIMEROS TEXTOS EN QUICHUA}

Una primera labor vinculada a la evangelización fue la instauración de colegios indígenas. El primero para niños indígenas fue el colegio de San Juan Evangelista fundado por fray Jodoco Ricke, franciscano, en 1551, y destinado a los hijos de los caciques locales. En 1556 toma el nombre de colegio San Andrés y en 1581 pasa a manos de los agustinos. En el colegio San Juan Evangelista se enseñaba en quichua y en castellano. Fray Jodoco Ricke también enseñaba agricultura, mecánica y carpintería. ${ }^{38}$

Por otro lado, como ya se adelantó, a los pocos años de la presencia evangelizadora ya se comienzan a escribir las primeras gramáticas y vocabularios en quechua, aimara e, incluso, en las lenguas prequichuas que se hablaban en el actual Ecuador.

La primera gramática del quechua que se conoce es la del dominico fray Domingo de Santo Tomás, publicada en 1560; ${ }^{39}$ sin embargo, la obra de Santo Tomás se encontraba ya redactada 10 años antes. Pero además, se tiene noticias de por lo menos otros dos textos escritos antes de la gramática de Santo Tomás. Para el caso de la Audiencia de Quito, se sabe que fray Martín

36. Bruce Mannheim, The Language of the Inka since the European Invasion (Austin: University of Texas Press), 254.

37. Ibíd., 69.

38. Samuel Íñiguez y Gerardo Guerrero, "Rasgos históricos de la educación indígena quichua en el Ecuador". En Pedagogía Intercultural Bilingüe. Experiencias de la Región Andina, comp. por Wolfgang Küper, 7-51 (Quito: Proyecto EBI / Abya-Yala, 1993), 12-13.

39. Santo Tomás, Grammatica o arte... 
de la Victoria escribió una gramática antes de 1550, aunque no se conoce el paradero actual del texto.

Sabemos que Fray Martín de Victoria, mercedario llegado a Quito con Benalcázar, abre la primera escuela de lenguas en el convento de La Merced, ya por el año de 1535, para enseñar quichua a los españoles y español a la nobleza local. Para esto compuso una gramática, que sería la primera ecuatoriana, si no se hubiese quemado y perdido probablemente en el incendio del convento mayor de Portoviejo, a fines del siglo XVI. ${ }^{40}$

Había disposiciones específicas para la elaboración de doctrinarios y confesionarios, como decíamos, para las lenguas prequichuas. Así, por ejemplo, se dispuso en el III Sínodo de Quito (1583), convocado por fray Luis de Solís. Ahí se dice:

Por la experiencia nos consta que en este Obispado hay diversidad de lenguas que no tienen ni hablan la del Cuzco ni la aimará, y que para que no carezcan de la doctrina cristiana es necesario hacer traducir el catecismo y confesionario en las propias lenguas: por tanto, conformándonos con lo dispuesto en el Concilio Provincial último, habiéndonos informado de las mejores lenguas [sic], ${ }^{41}$ que podrían hacer esto, nos ha parecido cometer este trabajo y cuidado a Alonso Núñez de S. Pedro y a Alonso Ruiz para la lengua de los llanos y tallana; y a Gabriel de Minaya, para la lengua Cañar y purguay; a Fr. Francisco de Jérez la de los Pastos; y a Andrés Moreno de Zúñiga y Diego Bermudez Presbítero para la lengua quillasinga; a los cuales encargamos lo hagan con todo cuidado y brevedad, pues de ello será Nuestro Señor servido, y de nuestra parte se lo gratificaremos: y hechos los dichos Catecismos los traigan o envien ante Nos para que vistos y aprovados, puedan usar de ellos. ${ }^{42}$

Para el quechua, en los primeros tiempos se daban curso a las mismas disposiciones que venían desde Lima, donde ya desde el I y II Concilio limense (1551 y 1567), convocados por el arzobispo Jerónimo de Loayza, se invocaba el empleo de la lengua nativa en la evangelización, siguiendo los dictados del Concilio de Trento (1545-1563). ${ }^{43}$

40. Matthías Abram, "Presentación". En Alonso de Huerta, Arte breve de la lengua quechua, 2. ${ }^{a}$ ed. (Quito: CEN / Proyecto EBI, 1993 [1616]), X.

41. Debe decir "de los mejores lenguas" que era como se les llamaba a los españoles que habían aprendido mejor las lenguas indígenas.

42. En Î̃iguez y Guerrero, "Rasgos históricos...", 15.

43. Rodolfo Cerrón-Palomino, "Diversidad y unificación léxica en el mundo andino". En El quechua en debate. Ideología, normalización y enseñanza, ed. y comp. por Juan Carlos Godenzzi, 205-235 (Cusco: CBC), 212. 
En 1580 se emitió una cédula real dirigida a los obispos de Lima, Charcas, Cusco y Quito que oficializaba la enseñanza del quechua en todos los centros de formación que tenían los sectores religiosos, imponiéndolo como condición para la ordenación sacerdotal y para el otorgamiento de doctrinas y beneficios. A manera de ejemplo, citamos parte de la cédula reproducida por Hartmann:

que no se ordenen de orden sacerdotal, ni den licencia para ello a ninguna persona que no sepan la lengua general de los dichos indios y sin que lleve fe y certificación del catedrático que leyere la dicha cátedra de que ha cursado en lo que se debe enseñar en ella, por lo menos un curso entero [...] aunque el tal ordenante tenga habilidad y suficiencia en la facultad que la iglesia y sacros canones manda; pues para el enseñamiento y doctrina de los dichos indios lo más importante es saber la dicha lengua". ${ }^{4}$

A tal fin se creó la cátedra de enseñanza de quichua, inaugurada en Quito el 17 de noviembre de 1581 y encomendada al dominico Hilario Pacheco. ${ }^{45}$ Luego, en el III Concilio Limense de 1583 se explicita una política de evangelización en las lenguas indígenas. Ello produce una serie de textos en quechua y en diversas lenguas. En concreto, se dispuso que entre 1583 y 1585 se elaboraran tres obras que se consideraban fundamentales para la evangelización: 1. la Doctrina Christiana y Cathecismo para la instrucción de los Indios; 2. el Confessionario para los curas de Indios; y, 3. el Tercero Cathecismo y exposición de la Doctrina Christiana. ${ }^{46}$

Para 1616, Alonso de Huerta sigue "desseando que [...] todos los q[ue] se ordenan, y los que van a Doctrinas a ser Curas, sepan muy bien la lengua general delos Indios". 47

Luego del primer momento de evangelización, durante el siglo XVI, la producción de materiales catequísticos (doctrinarios, devocionarios, confesionarios, etc.) se centró en las variantes centro y surperuanas, más específicamente en aquella variante denominada lengua del Cuzco. ${ }^{48}$ Será solo en el

44. Roswith Hartmann, "Apuntes históricos sobre la cátedra del quechua en Quito. Siglos XVI y XVII", Boletín de la Academia Nacional de Historia LIX, n. . 127-128 (1976): 20-41, 20-21.

45. Ibíd., 21; Íñiguez y Guerrero "Rasgos históricos...", 14. Como nota adyacente conviene citar el estudio de la misma Roswith Hartmann en torno a las destrezas del predicador quichua Diego Lobato de Sosa. Roswith Hartmann, “Un predicador quechua del siglo XVI". En Antropología del Ecuador. Memorias del Primer Simposio Europeo sobre Antropología del Ecuador, comp. por Segundo Moreno Yánez (Quito: Abya-Yala, 1989), 313-323.

46. Véase Moya, "Estudio introductorio", XIX.

47. Huerta, Arte breve..., 9.

48. La discusión sobre las denominaciones lengua general, chinchay estándar y chinchay inca puede encontrarse en Fernando Garcés, "Estudio introductorio". En Cuatro textos coloniales del quichua de la "Provincia de Quito" (Quito: Proyecto EBI, 1999), 34-36. 
siglo XVIII que nuevamente se reiniciará una producción en quichua para lo que entonces se denominaba la Audiencia de Quito.

\section{LA PRODUCCIÓN EN LA VARIANTE "ECUATORIANA"}

El contexto de producción de textos de evangelización y normativos cambió hacia fines del siglo XVIII debido a la política lingüística asimilacionista y antiindígena de Carlos III (1759-1788), a la expulsión de los jesuitas del Imperio español en 1767 y a la fuerte represión que siguió a las rebeliones de fines del siglo XVIII. Con respecto al último aspecto, la rebelión de Túpac Amaru fue solo el punto más alto de una serie de otras rebeliones que se dieron a lo largo del mundo andino. ${ }^{49} \mathrm{O}^{\prime}$ Phelan, por ejemplo, calcula que en los actuales Perú y Bolivia se dieron alrededor de 140 rebeliones entre 1708 y $1783,{ }^{50}$ al tiempo que en la "Provincia de Quito" se pueden identificar por lo menos 17 en el mismo siglo. ${ }^{51}$

La derrota de la rebelión trajo la firme resolución de parte de la administración colonial borbónica de eliminar la lengua y la cultura quechua. La sentencia de muerte contra Túpac Amaru tenía la siguiente instrucción: "Y para que estos indios se despeguen del odio que hen concebido [sic] contra los españoles [...] se vistan de nuestros [sic] costumbres españoles, y hablan la lengua castellana, se introducirá con más vigor que hasta aquí el uso de sus escuelas bajo las penas más rigorosas y justas contra los que no las usen". 52

El visitador Areche dio el plazo de cuatro años a todos los hablantes del quechua para aprender el castellano y abolió la cátedra establecida en la Universidad de San Marcos. Sin embargo, para este siglo tenemos que el quichua se ha convertido ya en lingua franca al interior de las misiones de Mainas. La situación lingüística de esta zona era de amplia diversidad y los

49. Garcés, "Estudio introductorio", 42-43.

50. Véase Scarlett O'Phelan, Un siglo de rebeliones anticoloniales. Perú y Bolivia 1700-1783 (Cusco: CBC, 1985). Stern, por su parte, sugiere tomar en cuenta la escasez de estudios sobre los levantamientos y sublevaciones del momento en la zona de la actual Bolivia, lo que implica que en términos numéricos la cifra podría ascender a mucho más de lo que conocemos. Véase Steve Stern, "La era de la insurrección andina, 1742-1782: una reinterpretación". En Resistencia, rebelión y conciencia campesina en los Andes. Siglo XVIII al XX, comp. por Steve Stern, 50-96 (Lima: IEP, 1987).

51. Véase Segundo Moreno Yánez, Sublevaciones indígenas en la Audiencia de Quito. Des-

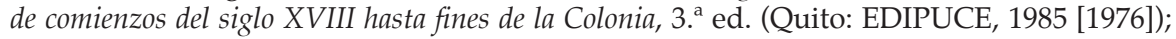
"Shamanismo y política en la última época colonial del Ecuador", Cultura II, n. ${ }^{\circ} 21$ b (1985): 487-509; Galo Ramón Valarezo, El regreso de los runas (Quito: COMUNIDEC, 1993).

52. Citado en Mannheim, The Language of the Inka..., 74. 
misioneros no lograban, a pesar de sus esfuerzos, tener hegemonía total en el gobierno eclesiástico y civil. ${ }^{53}$

Recordemos que a poco más de 20 años de haber ingresado los jesuitas a Mainas, Francisco de Figueroa pide "Que todos los Padres procuren en todo caso ir introduciendo la lengua general del Inca en las reducciones [...]. Este idioma es el que más se les pega y en que más fácilmente entran, como se ve por experiencia, por ser el más acomodado a su capacidad, y que en las elocociones [sic], partículas y modos de hablar, corresponde con sus lenguas naturales". ${ }^{54}$

No se puede hablar, sin embargo, de una expansión total del quichua en la región. Para 1740 encontramos comunidades que mantienen sus lenguas y otras que se han apropiado medianamente del quichua. Así lo atestigua el sacerdote jesuita Juan Magnin:

La variedad y la complejidad de las lenguas del país es otra causa de aflicción. Qué puede hacer un misionero solo, con gente a la que no entiende y que no le entienden y a quien no puede ni siquiera hacer comprender por señas sus necesidades más urgentes y que trata en vano de volverlas evidentes. Si se puede tener intérpretes es un alivio, / pero como están inclinados a desertar cuando menos se piensa, un misionero se encuentra privado a menudo de sus servicios. En las antiguas reducciones en que se ha establecido la lengua del inca, estos inconvenientes se encuentran considerablemente disminuidos, pero subsiste con las mujeres que de ordinario no saben sino la lengua particular de su nación. ${ }^{55}$

Sin embargo, la política lingüística desplegada por los jesuitas iba por el lado de instaurar el quichua como lengua de relación en una zona lingüística compleja, al tiempo que se eliminaba la existencia de las lenguas existentes. Así se puede encontrar información sobre el tema, esparcida por aquí y por allá, en el diario del P. Manuel Uriarte (1750-1770). Por ello, Bayle afirma que "para abolir poco a poco la multitud de lenguas entre los indios (las del Marañón las calculaba el P. Vieyra en ciento cincuenta) y facilitarles el mutuo trato y ahorrar a los misioneros la fatiga de arremeter con todas las de su variable distrito, discurrieron acudir al sistema empleado por los reyes del Perú en las tierras conquistadas: enseñar la lengua general o inga" ${ }^{56}$

53. María Elena Porras, La Gobernación y el Obispado de Mainas. Siglos XVII y XVIII (Quito: Abya-Yala / TEHIS, 1987), 59.

54. Francisco de Figueroa, "Informe de las Misiones de el Marañon, Gran Pará o Rio de las Amazonas". En Historiadores y Cronistas de las Misiones. La Colonia y la República, 137170 (Puebla: Cajica, 1960 [1661]), 167-168.

55. Juan Magnin, Descripción de la Provincia y Misiones de Mainas en el Reino de Quito (Quito: Biblioteca Ecuatoriana Aurelio Espinosa Pólit / Sociedad Ecuatoriana de Investigaciones Históricas y Geográficas, 1998 [1740]), 242-243.

56. Bayle. En Manuel Uriarte, Diario de un misionero de Maynas (Iquitos: IIAP-CETA, 1750-1770), 112-113, nota 10. 
Como dato adicional, Porras afirma que, durante 1730 y 1760, la gobernación-misión de Mainas se movía entre una situación de conquista de nuevos pueblos y la desorganización administrativa, producida por la incapacidad de controlarlos y asimilarlos. ${ }^{57} \mathrm{Y}$ es en este contexto que ocurre la salida de los jesuitas de 1767, dejando en "abandono" a los pueblos en los que hacían presencia.

De su lado, Calvo Pérez señala que el obligado desinterés por las lenguas indígenas, "nacido de la política expansionista del español como lengua, contrasta con la curiosidad científica por el lenguaje que surge con el llamado Siglo de las Luces" ${ }^{58}$ Las comunidades religiosas, al continuar con su labor evangelizadora, echarán mano de las gramáticas y diccionarios elaborados por sus antecesores, copiándolas o reproduciéndolas pedagógicamente. Así, los textos de este período, sobre todo las gramáticas y vocabularios, serán fundamentalmente adaptaciones y reducciones de las obras monumentales producidas en el primer siglo de presencia evangelizadora en los Andes. ${ }^{59}$

Presentamos a continuación una lista de los principales textos de los que se tiene referencia con respecto a la variedad ecuatoriana para la época colonial. Esta lista no es exhaustiva y de muchos de los textos apenas conocemos su título; sin embargo, nos puede dar una idea de la producción lingüística y catequética en quichua durante el momento de la Colonia. Lo más importante es que los textos a los que podemos acceder contienen información importante sobre el estado interno de la lengua en sus distintos niveles (fonológico, morfosintáctico, semántico). Hemos seguido fundamentalmente los textos citados por Rivet \& Créqui-Montfort, Roswith Hartmann, Romero Arteta y nuestro propio trabajo. ${ }^{60}$

En 1725, Luis Francisco Romero, $14^{\circ}$ obispo de Quito, publica una carta pastoral titulada "A los venerables curas de su Obispado, sobre la omissión y descuido en que los yndios, sus Feligreses cumplan con el precepto annual de comulgar, y el de recebir el Santissimo Viatico en el articulo de la muer$t^{\prime \prime}$. En esta carta se encuentra incluido el "Catechismo para los yndios en

57. Porras, La Gobernación..., 52-53.

58. Julio Calvo Pérez, "Noticias y aportaciones lingüísticas sobre el quechua en el siglo XVIII". En Del Siglo de Oro al Siglo de las Luces. Lenguaje y sociedad en los Andes del siglo XVIII, 33-57 (Cusco: CBC, 1995), 33.

59. Véase Santo Tomás, Grammatica o arte...; Arte, y vocabvlario...; González Holguín, Gramática y Arte..., Vocabulario de la lengua...; Huerta, Arte breve....

60. Paul Rivet y Georges Créqui-Montfort, Bibliographie des langues aymará et kichua, vol. I (1540-1875) (París: Institut D'Ethnologie, 1951); Roswith Hartmann, "Fuentes quechuas de la época colonial con referencia al Ecuador", Pueblos indígenas y educación, n. ${ }^{\circ}$ 31-32, año 7 (1994): 71-98; Oswaldo Romero Arteta, “Introducción”, Llacta, n. 20 (1964): III-XXXV; Garcés, Cuatro textos coloniales.... 
lengua", en versión bilingüe quichua-castellano. ${ }^{61}$ Parte de la carta y el texto íntegro del catecismo fue publicado por Grimm. ${ }^{62} \mathrm{El}$ dato bibliográfico del "Catechismo" es citado por Hartmann a partir de la cita y texto de Rivet y Créqui-Montfort. ${ }^{63}$ Para el siglo XVIII, "se puede añadir una "Gramática de lengua inga", impresa en 1762, en la que figura como autor Manuel Messía, un jesuita de Latacunga, sobre la cual se carece de más datos. El manuscrito de una nueva edición "más exacta" juntó [sic] con un "Diccionario" que Messía había preparado por orden del Provincial de Quito hasta 1766 se perdió antes de llegar a la imprenta en Lima". ${ }^{64}$

Para el siglo XVIII tenemos también un Vocabulario de la lengua Castellana, la del Inga y Xebero, atribuido a Samuel Fritz; tiene 35 folios y 1.300 entradas. Hartmann dice que este manuscrito anónimo se halla depositado en la Public Library de Nueva York y que ha sido analizado por María Susana Cipolletti en $1992 .{ }^{65}$

Hay un documento llamado "De lingua generali, vulgo dicta: del Ynga" que se encuentra incluido en Gründliche Nachrichten über die Verfassung von Maynas in Süd-Amerika bis 1768 de un jesuita alemán llamado Franz Xaver Veigl. (El último texto citado se lo puede encontrar en Christoph Gottlieb von Mur (ed.) Reisen einiger Missionarien der Gesellschaft Jesu in Amerika. pp. 1-441. Nürnberg). ${ }^{66}$

Entre 1750 y 1770 el padre Manuel Uriarte, jesuita, escribió su Diario de un misionero de Maynas. Al final del mismo se encuentra una serie de oraciones, cánticos y doctrina escrita en quichua. ${ }^{67}$

El texto de autor Anónimo y fecha desconocida, titulado Arte de la lengua Jeneral de Cusco llamada Quichua, editado por Sabine Dedenbach-Salazar Sáenz y luego por Fernando Garcés podría tratarse del mismo citado por Rivet y Créqui-Montfort, ${ }^{68}$ que se encuentra en el Archivo Nacional de Bogotá

61. Rivet y Créqui-Montfort, Bibliographie..., 141-147.

62. Juan Manuel Grimm, La lengua quichua (dialecto de la República del Ecuador) (Quito: Proyecto EBI, 1989 [1896]), XXXI-XXXVII.

63. Hartmann, "Fuentes quechuas...", 74.

64. Ibíd., 80. El dato de la Gramática de Messía se encuentra en Rivet y Créqui-Montfort, Bibliographie..., 742.

65. "Un manuscrito tucano del siglo XVIII: ejemplos de continuidad y cambio en una cultura amazónica (1753-1990)”, Revista de Indias LII, n. ${ }^{\circ}$ 194: 181-194. Madrid. Colección Vacas-Galindo (abreviada Col. VG). Colección de documentos para la historia del Ecuador por el R. P. Fray Enrique Vacas Galindo (copias del Archivo General de Indias) en el convento de Santo Domingo de Quito. 4 series: I. ${ }^{a}$ serie - Patronado, II. ${ }^{a}$ serie - Cedularios, III. ${ }^{a}$ serie - Eclesiástico, IV. a serie-Secular"; Hartmann, "Fuentes quechuas...", nota 11.

66. Véase Hartmann, "Fuentes quechuas...".

67. Uriarte, Diario....

68. Sabine Dedenbach-Salazar Sáenz, ed., Una gramática colonial del quichua del Ecuador 
(Sección: Ortega Ricaurte, Fondo Caciques e Indios, caja n. $\left.{ }^{\circ} 27\right)$. El documento está formado por 34 folios de $235 \mathrm{~mm} \times 180 \mathrm{~mm} .^{69}$

El denominado Anónimo de Praga tiene por título Breve inst [r]uccion o arte para entender la lengua comun de los indios. El manuscrito se conserva en la Biblioteca Estatal de Praga, estante VIII H $81 .{ }^{70}$ Más conocido es el Vocabulario de la lengua índica de Juan de Velasco de cerca de 1787. Fue publicado en la revista Llacta en 1964. El Vocabulario A (quichua-castellano), no encontrado, tendría aproximadamente 3000 vocablos, mientras el B (castellano-quichua), $1450 .{ }^{71}$

En 1753, se publicó la Breve Instruccion, o Arte para entender la lengua comun de los Indios, segun se habla en la Provincia de Quito, atribuida a Tomás Nieto Polo del Águila, oriundo de Popayán y quien fue provincial de los jesuitas al momento de la publicación de la Breve Instrucción. ${ }^{72}$ También de 1753 es el manuscrito de 75 folios que reposa en la Biblioteca Pública de Nueva York bajo el título Arte de lengua de las Miciones, del Río Napo de la Nación de los Infieles Qquenque hoyos: ydioma General de los demás de ese Río. Payohuahuajes: Senzehuajes: Ancoteres: en Cavellados: juntamente tiene la Doctrina Christiana en dicha lengua y en la del ynga. La sección del quichua del Napo se encuentra inédita. ${ }^{73}$

Para el siglo XVIII, Rivet y Créqui-Montfort citan unos manuscritos del jesuita Guilliel Grebmer titulado Exhortationum Moralium pro Indis, præsertim harum Missionum duæ partes. ${ }^{74}$ Se trata de dos volúmenes, con el índice y los títulos en latín pero con el texto escrito en quichua. Rivet y Créqui-Montfort afirman que el padre Grebmer nació en Ersingen (Alemania) el 4 de julio de 1685, entró a la Compañía de Jesús el 14 de septiembre de 1705 y murió en Quito el 11 de junio de 1766.

Romero Arteta también cita, a partir de Brinton, un manuscrito inédito titulado Elementi della Lingua Quichua, que habría sido escrito por un jesuita erudito que viajó por Ecuador y Perú. ${ }^{75}$ Finalmente, en la Biblioteca Jacinto Jijón y Caamaño se encontraría un manuscrito de 108 páginas titulado Vocabulario de Lengua Inga, con una leyenda al final: "Es del uso del Hermano Marcos Viescas", razón por la que no se puede saber si se trata del autor o del propietario. ${ }^{76}$

(Bonn / St. Andrews: Estudios Americanistas de Bonn / University of St. Andrews, 1993); Garcés, Cuatro textos..., 205-256; Rivet y Créqui Montfort, Bibliographie..., 126-127.

69. Según información proporcionada por Carlos Enrique Pérez en marzo de 1998, el Arte podría encontrarse en el Fondo Caciques e Indios, caja 9, carpeta 30, fol. 8-53.

70. Véase Calvo, "Noticias y aportaciones..."; Garcés, Cuatro textos..., 182-204.

71. Ibíd., 50-80.

72. Ibíd., 47-50.

73. Romero, "Introducción", XIX.

74. Rivet y Créqui-Montfort, Bibliographie..., 206-208; véase también Hartmann, "Fuentes quechuas...", 77 y nota 4.

75. Romero, “Introducción”, XX.

76. Ibíd. 
Como vemos, dispondríamos aquí de material básico para esbozar las características que habría tenido el proceso de elaboración lingüística de nuestra variedad durante el período colonial y como medio de evangelización.

\section{EL QUICHUA REPUBLICANO}

Entre fines del siglo XVIII y fines del XIX tenemos un gran vacío en la producción de materiales lingüísticos y catequísticos en referencia al quichua. Ello se debe, probablemente, a la restricción de escribir en quichua que se dio después de los levantamientos insurreccionales de toda el área andina que se produjeron en la segunda mitad del XVIII y que ya fueron mencionados. En este siglo y en lo que actualmente es Ecuador, se produjeron, por lo menos, catorce grandes sublevaciones entre 1707 y $1797 .{ }^{77}$

Por contrapartida, las últimas décadas del siglo XIX fueron sumamente productivas en la producción en y sobre el quichua ecuatoriano. Seguían pesando concepciones civilizatorias en favor del castellano y en contra del quichua como, por ejemplo, la del gran historiador jesuita Federico González Suárez. Para él,

El Gobierno español dictó providencias muy laudables en beneficio de los indios; pero no se cumplieron y los humanitarios propósitos de la Corona, respecto de los indios quedaron frustrados; una de esas previsoras y excelentes providencias fué la de que se extinguieran las lenguas maternas de los indígenas, para que éstos hablaran la castellana; la extinción debía hacerse poco á poco y gradualmente. Por desgracia, esta medida no se llevo á cabo en todas las provincias de la Audiencia de Quito. ${ }^{78}$

Y más adelante afirma: "para civilizar á los indios es necesario transformarlos y la transformación social de ellos depende de su lengua materna. Cuando se logre que en el Ecuador no haya más que una sola lengua, entonces no habrá más que un solo pueblo". ${ }^{79}$

Pero más allá de las opiniones de González Suárez, este momento es de enorme riqueza en dos sentidos. Por un lado, en cuanto se reanuda con vigor la producción lingüística en y sobre el quichua, aunque siempre vinculada a los intereses de evangelización; por otro lado, surge una disputa sumamente interesante en torno a la validez o no del quichua para expresar ideas

77. Garcés, Cuatro textos..., 42-43.

78. Federico González Suárez, Historia general de la República del Ecuador, vol. II (Quito: Casa de la Cultura Ecuatoriana, 1970 [1892]), 1413.

79. Ibíd., 1414. 
abstractas y espirituales. Como muestra de lo primero, baste recordar las publicaciones de Julio Paris, Juan Manuel Grimm, Manuel Guzmán y Juan Gualberto Lobato. ${ }^{80}$

Con respecto a la discusión mencionada, ya presentada en otro lugar, ${ }^{81}$ entre fines del siglo XIX e inicios del XX tenemos dos posiciones lideradas cada una por intelectuales o religiosos de la época. Por un lado, el doctor Luis Cordero y el lazarista Juan Manuel Grimm; y, por otro, el conocido escritor y poeta Juan León Mera junto con el jesuita Manuel Guzmán. Para Cordero, el quichua es una lengua pobre en cuanto capacidad de designación de objetos morales y filosóficos, ${ }^{82}$ mientras Grimm se quejaba de la dificultad de "expresar las ideas religiosas en un idioma tan estrecho como el quichua", ${ }^{83}$ debido a su escaso vocabulario y posibilidades sintácticas. Por el contrario, para Juan León Mera el quichua es una lengua expresiva, armoniosa y dulce al punto que "no hay objeto material ó abstracto que no anime con vivísimos colores é imágenes hermosas y variadas". ${ }^{84}$ Guzmán, por su parte, critica a quienes califican al quichua de lengua pobre; lo hacen porque no lo conocen o lo conocen superficialmente; en tal sentido, "es falso lo que asegura un grave autor, que en quichua no se puede exponer todos los Dogmas y Misterios de nuestra Santa Religión, por falta de términos para explicarlos" ${ }^{85}$

Más allá de esta disputa nos parece interesante resaltar la figura del redentorista Lobato. ${ }^{86}$ Nacido en Cacha, cerca de Riobamba, tenía como lengua materna el quichua. Fue el primer sacerdote redentorista indio en Ecuador y

80. Julio Paris, Catecismo para indijenas (Cuenca: Impr. Andrés Cordero, 1881); Gramática de la lengua quichua actualmente en uso entre los indígenas del Ecuador, 4. ${ }^{a}$ ed. (Quito: CEN / Proyecto EBI, 1993 [1892]); Ecuador runacunapac rezana libro (Einsiedeln: Benziger y Co., Tipografía de la Santa Sede Apostólica, 1893); Juan Manuel Grimm, La lengua quichua...; Vademécum para párrocos de indios quichuas (Friburgo de Brisgovia: B. Herder / Librero-Editor Pontificio, 1903). Manuel Guzmán, Gramática de la lengua quichua (dialecto del Ecuador) (Quito: Tip. de la "Prensa Católica", 1989 [1920]); Método práctico de preparar a indios para la confesión y comunión seguido de las partes principales de la Doctrina Cristiana (Quito: Tip. de la "Prensa Católica", 1920). Juan Gualberto Lobato, Diospac ruraicuna jahua. Runacunapac causai jahuapi. Historia sagrada en quichua (Turnhout: Brepols, 1922).

81. Véase Garcés, ¿Colonialidad o interculturalidad?...

82. Luis Cordero, Diccionario quichua-castellano y castellano-quichua, 5. ${ }^{\mathrm{a}} \mathrm{ed}$. (Quito: CEN / Proyecto EBI, 1992 [1895]), 369.

83. Grimm, Vademécum..., CLXII.

84. Juan León Mera, Ojeada histórico-crítica sobre la poesía ecuatoriana (Guayaquil: Ariel, s. f. [1868]), 19.

85. Guzmán, Método práctico..., 52.

86. El nombre completo del padre Lobato era Juan Gualberto Nicolás Lobato Duchicela Huaraca. Ruth Moya, "Estudio introductorio". En Julio Paris, Gramática de la lengua quichua actualmente en uso entre los indigenas del Ecuador, 4. ${ }^{a}$ ed. (Quito: CEN / Proyecto EBI, 1993), XXIII. 
en Sudamérica. ${ }^{87}$ Dice Ruth Moya que "fue prefecto de la Sección Indígena de la Sagrada Familia, al tiempo que profesor de canto y de quichua y [...] firmemente convencido de la necesidad de revitalizar el quichua en las misiones" ${ }^{88}$

La figura del padre Lobato, quien pasó varios años de su vida en Perú, se entronca muy bien con el movimiento de evangelización en quichua de fines del siglo XIX e inicios del XX. Por eso afirma Moya que

La catequización en quichua era la política oficial de toda la iglesia, pues el II Concilio Provincial Quitense, celebrado en enero de 1869, determinaba la traducción al quichua del Catecismo elemental y medio, política que a su vez se confirmó en el IV Concilio Provincial Quitense, de mayo de 1885, y en el que se dispone se establezcan las cátedras de quichua en todos los Seminarios, especialmente en el Seminario central. En el caso específico de los redentoristas estos dedicaron gran parte de sus primeros esfuerzos en aprender el quichua y fue el [...] obispo de Riobamba, Monseñor Ignacio Ordóñez, quien enseñara el quichua a los redentoristas de Riobamba. No es de extrañarse que en esa línea se destacaran por entonces los redentoristas ecuatorianos J. G. Lobato, Ezequiel Bravo, Julio Maldonado, y entre los franceses, Julio Paris, Dupont, Eugenio Hengbart. ${ }^{89}$

\section{A MANERA DE CONCLUSIÓN}

Contamos hoy con una importante producción de estudios lingüísticos y filológicos sobre las que fueran llamadas lenguas generales en los Andes: el puquina, el aimara y el quechua. ${ }^{90}$ En ellas se ha trabajado desde la perspectiva de la lingüística histórica a partir de los materiales coloniales de los que se tienen noticias. Los esfuerzos han estado centrados en las variantes "peruanas", y con cierta razón, en el sentido de que la política lingüística precolonial se diseñó e implementó desde el centro del Imperio incaico y también fue el eje desde donde se diseñó la política lingüística del quechua pastoral. ${ }^{91}$ El interés por la variante chinchay histórica viene del hecho de que fue esta la variante que describió Santo Tomás y que se habría desplazado al norte en tiempos precoloniales. ${ }^{92}$

87. Ibíd., XII.

88. Ibíd., XXIV.

89. Ibíd.

90. La lista sería extensa. De manera referencial, se pueden consultar los trabajos de Rodolfo Cerrón-Palomino, Paul Heggarty, Cesar Itier, Bruce Mannheim, Gerald Taylor y el ya fenecido Alfredo Torero.

91. Cerrón-Palomino, "Las primeras traducciones..."; Durston, Pastoral Quechua. The History...

92. Alfredo Torero, El quechua y la historia social andina (Lima: Universidad Ricardo Palma, 1974); "El comercio lejano y la difusión del quechua. El caso de Ecuador", Revista 
Por otro lado, las obras catequéticas de los misioneros estaban vinculadas al programa de sustitución y extirpación religiosa (de "idolatrías"), y en este sentido es claro que no les interesaba la lengua como trasmisora de la cultura andina sino como medio para implantar la doctrina..$^{93}$

No obstante, el manejo de las fuentes coloniales e incluso republicanas puede arrojar luces importantes tanto sobre la historia de las lenguas y sus ideologías, tal como se ha visto, como sobre aspectos de lingüística histórica. Así, a manera de ejemplo, en un trabajo previo, gracias a la revisión de varios materiales de los siglos XVIII y XIX aquí citados, se ha podido constatar la existencia histórica de los sufijos nominales de persona hasta el primer cuarto del siglo XX, hoy prácticamente ausentes en el habla ecuatoriana y muy productivos en el quechua sureño. ${ }^{94}$

Como dice Ruth Moya, tras lo nefasto del celo por la extirpación de idolatrías que llevó adelante el proyecto colonial "por irónica contrapartida histórica, gracias a este mismo celo, se estimuló la impresión de las Artes del lenguaje y podemos contar ahora con testimonios y documentación tempranos de la lengua, la literatura oral y la cultura indígenas. ¡Contraste y paradoja coloniales!". ${ }^{95}$

Es en este sentido que hemos querido ofrecer este acercamiento a las fuentes de estudio del quichua ecuatoriano a partir de los testimonios dejados por representantes de la iglesia y con el fin de exhumar filones de nuestra historia lingüística. His lacrimis vitam damus.

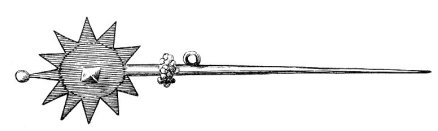

Andina, n. ${ }^{\circ} 4$ (1984): 367-389; “Acerca de la lengua Chinchaysuyo”. En Del Siglo de Oro al Siglo de las Luces, comp. por César Itier (Cusco: CBC, 1995); Idiomas de los Andes. Lingüística e historia (Lima: Horizonte, 2005). Rodolfo Cerrón-Palomino, "Contactos y desplazamientos lingüísticos en los Andes centro-sureños: el puquina, el aimara y el quechua", Boletín de arqueología PUCP, n. ${ }^{\circ} 14$ (2010): 255-282.

93. De hecho, como dice Ruth Moya, Alonso de Huerta "debió participar del entusiasmo por la extirpación de idolatrías". Moya, "Estudio introductorio". En Arte breve..., XXXI.

94. Fernando Garcés, "Sufijos nominales de persona en el quichua ecuatoriano". En Lexis, vol. XXI. n. ${ }^{\circ} 1,1997,85-106$.

95. Moya, "Estudio introductorio". En Arte breve..., XXXI. 


\section{FUENTES Y BIBLIOGRAFÍA}

\section{FUENTES PRIMARIAS PUBLICADAS}

Abram, Matthías. "Presentación". En Alonso de Huerta. Arte breve de la lengua quechua, 2. ${ }^{a}$ ed., IX-XI. Quito: Corporación Editora Nacional (CEN) / Proyecto EBI, 1993 [1616].

Arte y vocabolario en la lengva general del Perv llamada Quichua, y en la lengva Española. Lima: Antonio Ricardo, 1951 [1586].

Bertonio, Ludovico. Vocabvlario de la lengva Aymara. Arequipa: El Lector, 2006 [1612].

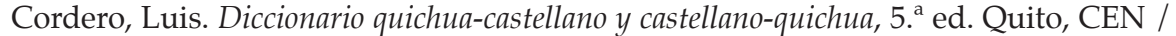
Proyecto EBI, 1992 [1895].

Figueroa, Francisco de. "Informe de las Misiones de el Marañon, Gran Pará o Rio de las Amazonas". En Historiadores y Cronistas de las Misiones. La Colonia y la República, 137-170. Puebla: Cajica, 1960 [1661].

Garcilaso de la Vega, Inca. Comentarios reales de los Incas. T. 3. Lima: Mercurio, 1988 [1609].

González Holguín, Diego, Gramática y Arte Nueva de la Lengua General de todo el Peru llamada lengua Qquichua o Lengua del Inca. Nueva edición revisada y corregida, 1842 [1607].

- Vocabulario de la lengua general de todo el Peru llamada lengua qquichua o del inca, 3. ' ed. Lima: Universidad Mayor de San Marcos, 1989 [1608].

González Suárez, Federico. Historia General de la República del Ecuador. Vol. II. Quito: Casa de la Cultura Ecuatoriana, 1970 [1892].

Grimm, Juan Manuel. La lengua quichua (Dialecto de la República del Ecuador). Edición facsimilar. Quito: Proyecto EBI, 1989 [1896].

- Vademécum para párrocos de indios quichuas. Friburgo de Brisgovia: B. Herder, Librero-Editor Pontificio, 1903.

Guzmán, Manuel. Gramática de la lengua quichua (dialecto del Ecuador). Edición facsimilar. Quito: Proyecto EBI, 1989 [1920].

- Método Práctico de Preparar a Indios para la Confesión y Comunión seguido de las partes principales de la Doctrina Cristiana. Quito: Tip. de "La Prensa Católica", 1920.

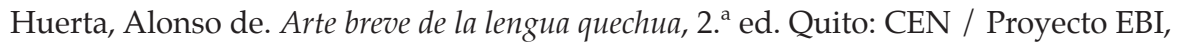
1993 [1616].

Lobato, Juan Gualberto. Diospac ruraicuna jahua. Runacunapac causai jahuapi. Historia sagrada en quichua. Turnhout: Brepols, 1922.

Magnin, Juan. Descripción de la Provincia y Misiones de Mainas en el Reino de Quito. Quito: Biblioteca Ecuatoriana Aurelio Espinosa Pólit / Sociedad Ecuatoriana de Investigaciones Históricas y Geográficas, 1988 [1740].

Mera, Juan León. Ojeada histórico-crítica sobre la poesía ecuatoriana. T. I. Guayaquil: Ariel, 1868.

Oré, Jerónimo de. Symbolo Catholico Indiano. Lima: Antonio Ricardo, 1598. 
Pachacuti Yamqui Salcamaygua, Joan de Santa Cruz. Relacion de antiguedades deste reyno del Piru. Lima / Cusco: Instituto Francés de Estudios Andinos (IFEA) / Centro de Estudios Regionales Andinos Bartolomé de Las Casas (CBC), 1993 [c. 1613].

Paris, Julio. Catecismo para los indijenas. Cuenca: Impr. Andrés Cordero, 1881. . Ecuador runacunapac rezana libro. Einsiedeln: Benziger y Co., Tipografía de la Santa Sede Apostólica, 1893.

. Gramática de la lengua quichua actualmente en uso entre los indígenas del Ecuador, 4. ${ }^{\text {a }}$ ed. Quito: CEN / Proyecto EBI, 1993 [1892].

Santo Tomás, Domingo de. Grammatica o arte de la lengua general de los indios de los reynos del Peru. Lima: CBC, 1995 [1560].

Tercer Concilio Limense. Doctrina Christiana y Catecismo para instrvccion de los Indios, y de las demas personas, que han de ser enseñadas en nuestra sancta Fé. Lima: Antonio Ricardo, Impressor, 1584.

Uriarte, Manuel. Diario de un misionero de Maynas. Iquitos: IIAP-CETA, 1986 [17501770].

\section{FUENTES SECUNDARIAS}

Calvo Pérez, Julio. “Noticias y aportaciones lingüísticas sobre el quechua en el siglo XVIII". En Del Siglo de Oro al Siglo de las Luces. Lenguaje y Sociedad en los Andes del Siglo XVIII, compilado por César Itier, 33-57. Cusco: CBC, 1995.

Cerrón-Palomino, Rodolfo. "Contactos y desplazamientos lingüísticos en los Andes centro-sureños: el puquina, el aimara y el quechua". Boletín de arqueología PUCP, n. ${ }^{\circ} 14$ (2010): 255-282.

. "Diversidad y unificación léxica en el mundo andino". En El quechua en debate. Ideología, normalización y enseñanza, compilado y editado por Juan Carlos Godenzzi, 205-235. Cusco: CBC, 1992.

. "Las primeras traducciones al quechua y al aimara". En Sobre las huellas de la voz. Sociolingüística de la oralidad y la escritura en su relación con la educación, compilado por Luis Enrique López e Ingrid Jung, 96-114. Madrid / Cochabamba / Bonn: Morata / PROEIB-Andes / DSE, 1998.

. "Un texto desconocido del quechua costeño (s. XVI)". Revista Andina 9, n. ${ }^{\circ} 2$ (1991): 393-413. http://www.revistaandinacbc.com/wp-content/ uploads/2016/ra18/ra-18-1991-03.pdf.

Dedenbach-Salazar Sáenz, Sabine, editora. Entrelazando dos mundos. Experimentos y experiencias con el quechua de la cristianización en el Perú colonial. Quito: AbyaYala, 2013.

. Una Gramática Colonial del Quichua del Ecuador. Bonn / St. Andrews: Estudios Americanistas de Bonn / University of St. Andrews, 1993.

Durston, Alan. "La escritura del quechua por indígenas en el siglo XVII. Nuevas evidencias en el Archivo Arzobispal de Lima (estudio preliminar y edición de textos)". Revista Andina 37 (II semestre 2003): 207-236. http: / / www.revistaandinacbc.com/wp-content/uploads/2016/ra37/ra-37-2003-08.pdf.

Pastoral quechua. The History of Christian Translation in Colonial Peru, 1550-1650.

Notre Dame: University of Notre Dame Press, 2007. 
Durston, Alan, y George Urioste. "Las peticiones en quechua del curato de Chuschi (1678-1679)". En El quipu colonial. Estudios y materiales, editado por Marco Curatola y José Carlos de la Puente, 379-440. Lima: Pontificia Universidad Católica del Perú (PUCP), 2013.

Garcés, Fernando. ¿Colonialidad o interculturalidad? Representaciones de la lengua y el conocimiento quechuas. La Paz: PIEB / Universidad Andina Simón Bolívar, 2009.

. De la voz al papel. La escritura quechua del Periódico CONOSUR Nawpaqman. La Paz: CENDA / Plural, 2005.

. "Estudio introductorio". En Cuatro textos coloniales del quichua de la "Provincia de Quito", 9-126. Quito: Proyecto EBI, 1999.

- "Las letras, las palabras y el orden: acerca de ortografías, gramáticas y vocabularios quechuas". Página y signos 5, n. 7 (2011): 13-41.

. "Sufijos nominales de persona en el quichua ecuatoriano". Lexis XXI, n. ${ }^{\circ}$ 1 (1997): 85-106. http:// revistas.pucp.edu.pe/index.php/lexis/article/ view $/ 7393 / 7616$.

Guamán Poma de Ayala, Felipe. "Nueva Coronica y Buen Gobierno, 1615". En The Guaman Poma Website. http:/ / www.kb.dk/ permalink/2006/poma/info/en/ frontpage.htm.

Hartmann, Roswith. "Apuntes históricos sobre la cátedra del quechua en Quito. Siglos XVI y XVII". Boletín de la Academia Nacional de Historia LIX, n. ${ }^{\circ} 127-128$ (1976): 20-41.

. "Fuentes quechuas de la época colonial con referencia al Ecuador". Pueblos Indígenas y Educación 7, n. ${ }^{\circ}$ 31-32 (1994): 71-98.

. "Un predicador quechua del siglo XVI". En Antropología del Ecuador. Memorias del Primer Simposio Europeo sobre Antropología del Ecuador, compilado por Segundo Moreno Yánez, 313-323. Quito: Abya-Yala, 1989

Íñiguez, Samuel, y Gerardo Guerrero. "Rasgos históricos de la educación indígena quichua en el Ecuador". En Pedagogía Intercultural Bilingüe. Experiencias de la Región Andina, compilado por Wolfgang Küper, 7-51. Quito: Proyecto EBI / Abya-Yala, 1993.

Itier, César. "Estudio y comentario lingüístico". En Joan de Santa Cruz Pachacuti Yamqui Salcamaygua, Relación de antigüedades deste reyno de Piru, 127-178. Lima / Cusco: IFEA / CBC, 1993.

- "Lengua general y comunicación escrita: cinco cartas en quechua de Cotahuasi-1616". Revista Andina 9, n. ${ }^{\circ} 1$ (1991): 65-107. http:/ / www.revistaandinacbc. com/wp-content/uploads/2016/ra17/ra-17-1991-03.pdf.

Lienhard, Martín. La voz y su huella. Escritura y conflicto étnico-cultural en América Latina 1492-1988, 3. ${ }^{a}$ ed. Lima: Horizonte, 1992 [1990].

Mannheim, Bruce. The Language of the Inka since the European Invasion. Austin: University of Texas Press, 1991.

Moreno Yánez, Segundo. Sublevaciones indígenas en la Audiencia de Quito. Desde comienzos del siglo XVIII hasta fines de la Colonia, 3. ${ }^{a}$ ed. Quito: EDIPUCE, 1985 [1976].

Moya, Ruth. "Estudio introductorio". En Alonso de Huerta, Arte breve de la lengua quechua, 2. ${ }^{\text {a }}$ ed., XIII-XXXII. Quito: CEN / Proyecto EBI, 1993. 
- "Estudio introductorio". En Julio Paris, Gramática de la lengua quichua actualmente en uso entre los indígenas del Ecuador, 4. ${ }^{\text {a }}$ ed., VII-XXVII. Quito: CEN / Proyecto EBI, 1993.

O'Phelan, Scarlett. Un siglo de rebeliones anticoloniales. Perú y Bolivia 1700-1783. Cusco: CBC, 1985.

Porras, María Elena. La Gobernación y el Obispado de Mainas. Siglos XVII y XVIII. Quito: Abya-Yala / TEHIS, 1987.

Pratt, Mary Louise. Ojos imperiales. Literaturas de viajes y transculturación. Ciudad de México: Fondo de Cultura Económica, 2010.

Ramón Valarezo, Galo. El Regreso de los Runas. Quito: COMUNIDEC, 1993.

Rivet, Paul, y Georges Créqui-Montfort. Bibliographie des langues aymará et kichua. Vol. I (1540-1875). París: Institut D’Ethnologie, 1951.

Romero Arteta, Oswaldo. “Introducción”. Llacta 20 (1964), III-XXXV.

Salomon, Frank. "Shamanismo y política en la última época colonial del Ecuador". Cultura II, n. ${ }^{\circ} 21 \mathrm{~b}$ (1985): 487-509.

Stern, Steve. "La era de la insurrección andina, 1742-1782: una reinterpretación". En Resistencia, rebelión y conciencia campesina en los Andes. Siglos XVIII al XX, compilado por Steve Stern, 50-96. Lima: Instituto de Estudios Peruanos (IEP), 1990 [1987].

Taylor, Gerald. Camac, camay y camasca y otros ensayos sobre Huarochirí y Yauyos. Lima / Cusco: IFEA / CBC, 2000.

. "Un documento quechua de Huarochirí-1607". Revista Andina 3, n. 1 (1985): 157-185, http:/ / www.revistaandinacbc.com/wp-content/uploads/2016/ ra05/ra-05-1985-06.pdf. . Ritos y tradiciones de Huarochirí del siglo XVII. Lima: IEP, 1987.

Torero, Alfredo. "Acerca de la lengua Chinchaysuyo". En Del Siglo de Oro al Siglo de las Luces, compilado por César Itier, 13-31. Cusco: CBC, 1995.

"El comercio lejano y la difusión del quechua. El caso de Ecuador". Revista Andina 2, n. ${ }^{\circ} 2$ (1984): 367-389.

. El quechua y la historia social andina. Lima: Universidad Ricardo Palma, 1974. . Idiomas de los Andes. Lingüística e historia. Lima: Horizonte, 2005. 